\title{
Federalismo, Vinculação, \\ Fundeb, VAAT e CAQ
}

\section{Federalism, Binding}

Fundeb, VAAT and CAQ

\author{
Federalismo, Vinculación, \\ Fundeb, VAAT y $C A Q$
}

\section{PAULO DE SENA MARTINS*}

Câmara dos Deputados, Brasília- DF, Brasil

RESUMO: Este artigo aborda as origens conceituais e bases legais e constitucionais do Custo Aluno Qualidade e discute caminhos para superar os obstáculos à sua implementação, dado o insucesso de sua garantia nos espaços dos poderes Executivo, Legislativo e Judiciário, apesar de constar expressamente como estratégia/meta do Plano Nacional de Educação (PNE). Aponta a necessidade de três convergências técnicas e política: entre o CAQ e o Fundeb, principal instrumento de financiamento da educação básica; entre o CAQ e o "valor aluno-ano total", critério de distribuição da complementação da União ao Fun$\mathrm{deb}$, indicado em proposta debatida no Congresso Nacional, e entre o CAQ e o federalismo, de forma a buscar equilíbrio e equidade a partir do exercício da solidariedade federativa, com papel predominante, mas não único, da União.

Palavras-chave: Fundeb. Valor aluno- ano total. Custo Aluno Qualidade. Vinculação. Desvinculação. Federalismo.

ABSTRACT: This paper discusses the conceptual and legal and constitutional basis of Cost of Quality Education per Student (CAQ) and also ways to overcome the obstacles to its implementation, given the failure of its guarantee in the Executive, Legislative and Judiciary,

* É doutor em Educação pela Universidade de Brasília. Mestre em Direito Penal pela Universidade de São Paulo. Atua como consultor legislativo da área de Educação, Cultura e Desporto na Câmara dos Deputados. E-mail: <paulo.martins@camara.leg.br>. 
although it is expressly a strategy/goal of the National Education Plan (PNE). It points to the need for three technical and political convergences: between CAQ and the Fund for Maintenance and Development of Basic Education and Educational Professionals (Fundeb), which is the main financing instrument for basic education; between the CAQ and the "total student-year cost", a criterion for distributing the Union's complement to Fundeb, indicated in a proposal debated in the National Congress, and between the CAQ and federalism, in order to seek balance and equity through the practice of Federative Solidarity, with the predominant, but not unique role, of the Union.

Keywords: Fundeb. Student per year cost. Quality Student Cost. Binding Untying. Federalism.

RESUMEN: Este artículo discute los orígenes conceptuales y la base legal y constitucional del Costo Alumno-Calidad y discute formas de superar los obstáculos para su implementación, dado el fracaso de su garantía en los poderes Ejecutivo, Legislativo y Judicial, aunque conste expresamente como una estrategia/objetivo del Plan Nacional de Educación(PNE). Señala la necesidad de tres convergencias técnicas y políticas: entre el Costo Alumno-Calidad (CAQ en portugués) y el Fundeb, el principal instrumento financiero para la educación básica; entre el CAQ y el "valor alumno-año total", un criterio de distribución de la complementación de la Unión al Fundeb, indicado en propuesta debatida en el Congreso Nacional, y entre el CAQ y el federalismo, para buscar el equilibrio y la equidad desde el ejercicio de la solidaridad federativa, con el papel predominante, pero no único, de la Unión.

Palabras clave: Fundeb. Valor alumno-año total. Costo Alumno-Calidad.

Vinculación. Desvinculación. Federalismo.

\section{Origens conceituais}

\footnotetext{
A final dos anos 80 do século $X X$, mais especificamente, sob o impacto da Constituição de 1988, que consagrou um desenho que permitiu desenvolver 1 as políticas públicas educacionais, inclusive as de financiamento da educação, (MARTINS,2019) foi formulada a ideia do custo aluno qualidade, em texto de Ediruald de Mello, que defendia, para definir o montante de recursos necessários ao financiamento do ensino, a ideia de um padrão de qualidade cujo custo seria
} 
tecnicamente rateado pela matrícula projetada, gerando o que decidi chamar de coeficiente de custo/aluno/qualidade, que servirá como unidade de custo a ser usada na projeção dos recursos a serem repassados às escolas com base em sua matricula prevista e que poderão ser corrigidos posteriormente com base na matrícula efetiva (MELLO, 1989, p.52).

Preconizava uma "política agressiva de redistribuição de recursos", baseada nessa medida de "necessidade educacional": o custo aluno qualidade. Para financiá-lo propunha que se calculasse

o montante de recursos disponíveis por aluno em cada nível de governo responsável pelo ensino público gratuito, tomando-se por base o esforço mínimo exigido na Constituição. As diferenças entre os recursos disponíveis por aluno em um determinado nível de governo e o custo/aluno/qualidade será coberta pelo nível ou níveis imediatamente maiores". Por exemplo, quando os recursos municipais de uso obrigatório no ensino não forem suficientes para financiar o custo/aluno/qualidade nas escolas municipais, o estado respectivo e/ou a União completarão as diferenças até equalizá-las (MELLO, 1989, p.53).

Ao debater das necessidades educacionais, expressas pela adoção das matrículas na escola pública como unidade de custo, o autor agregou a dimensão federativa, ao reivindicar a política agressiva de redistribuição de recursos: era preciso saber o grau de suficiência de recursos dos municípios para a execução de sua tarefa em relação à educação e, caso estes não fossem ao menos iguais ao necessário, "as outras esferas de governo complementariam os recursos municipais" (MELLO, 1989; 1991; SENA, 2014).

O texto constitucional então recém aprovado já continha os elementos para dar a base constitucional ao Custo Aluno Qualidade(CAQ): o art. 106, VII previa a "garantia de padrão de qualidade" e o Art. 214, III, ao dispor acerca do Plano Nacional de Educação, indicava que este deveria conduzir, entre outros objetivos, à "melhoria da qualidade do ensino".

As emendas constitucionais que introduziram os fundos contábeis: Emenda no 14 (Fundo de Manutenção e Desenvolvimento do Ensino Fundamental e de Valorização do Magistério [Fundef]) e Emenda nº 53 (Fundo de Manutenção e Desenvolvimento da Educação Básica [Fundeb]), mantiveram o espírito e a identidade da Carta de 1988 (MARTINS, 2018a).

A Emenda Constitucional (EC) nº 14/1996 (Fundef) introduziu a ideia do padrão mínimo de qualidade, ao prever em sua redação

que a função supletiva e redistributiva da União deveria "garantir equalização de oportunidades educacionais e padrão mínimo de qualidade do ensino mediante assistência técnica e financeira" aos entes subnacionais (Art. 211, §1º);

[E], que a União, os estados, o Distrito Federal e os municípios ajustassem "progressivamente, em um prazo de cinco anos, suas contribuições ao Fundo, de forma a garantir um valor por aluno correspondente a um padrão mínimo de qualidade de ensino, definido nacionalmente" (art. 60, $\S 4^{\circ}$ ). 
Assim, deu novo contorno ao já previsto regime de colaboração, colocando-o a serviço da qualidade da educação, que integra o núcleo essencial do direito à educação (SENA,2014). E, para não deixar dúvidas acerca de como sustentar esse objetivo, erigiu a vinculação, princípio autônomo do direito educacional (e não mera exceção ao princípio da não-afetação do direito financeiro) em princípio constitucional sensível, com todas as graves sanções se não observado (intervenção federal).

Ainda nesse ano da promulgação daquela importante Emenda Constitucional, que preservou e ampliou a identidade constitucional no tema da educação, foram aprovadas a Lei do Fundef e a Lei de Diretrizes e Bases da Educação Nacional (LDB).

A Lei do Fundef (Lei no 9.424/96) previa a "busca do aumento do padrão de qualidade do ensino" (art.13, VI), entre os critérios a serem considerados para os ajustes progressivos de contribuições correspondentes a um padrão de qualidade de ensino definido nacionalmente.

Ao mesmo tempo, a LDB ( Lei nº 9.394/96), que estabelece a garantia de padrão de qualidade, como um dos princípios a partir dos quais o ensino deve ser ministrado (art. $3^{\circ}$, IX), dispôs que o dever do Estado para com a educação escolar pública será efetivado mediante a garantia de, entre outros, padrões mínimos de qualidade de ensino, definidos como "a variedade e quantidade mínimas, por aluno, de insumos indispensáveis ao desenvolvimento do processo de ensino-aprendizagem" (art.4º IX). E, ao prever (art. 75), que “a ação supletiva e redistributiva da União e dos estados será exercida de modo a corrigir, progressivamente, as disparidades de acesso e garantir o padrão mínimo de qualidade de ensino", trouxe a dimensão federativa, com a solidariedade federativa, ao responsabilizar, também, os estados e não apenas a União.

Se a Mello pode-se atribuir essa ideia pioneira do Custo Aluno-Qualidade ${ }^{1}$ (cujos fundamentos legais foram replicados na LDB, nos artigos $4^{\circ}$, 74 e 75 , em cuja formulação legislativa aquele autor teve participação decisiva como técnico da Câmara dos Deputados), o estudo inédito para propor um caminho de sua operacionalização, a partir de estudos, pesquisas e oficinas, foi desenvolvido anos depois (2002) pela Campanha Nacional pelo Direito à Educação. Tratava-se de, a partir da legislação citada, dar instrumentos para que o padrão mínimo de qualidade dirigisse a execução do antigo Plano Nacional de Educação (PNE), aprovado pela Lei 10.172/2001, que vigorou no período 2001-2010. A pergunta que motivou a construção do modelo foi: qual o investimento por aluno é necessário para que haja ampliação do acesso e melhoria da qualidade segundo o PNE? E o ponto de partida do CAQ é o já vislumbrado na LDB: o CAQ é calculado a partir dos insumos indispensáveis ao desenvolvimento dos processos de ensino e aprendizagem (CARREIRA e PINTO, 2007). 


\section{O que é que está (não) pegando?}

OCAQ foi por algum tempo o centro dos debates do Conselho Nacional de Educação (CNE), que chegou a produzir o parecer CNE/CEB nำ/2010 (BRASIL, 2010), nunca homologado pelo Executivo.

Mas, o problema maior foi uma indefinição no âmbito interno do MEC. Foi esclarecedor o depoimento do professor Mozart Neves, que no CNE fora o relator da proposta do CAQ, em audiência pública no Senado Federal no dia 13 de maio de 2015: a Secretaria de Educação Básica (SEB), o Instituto Nacional de Estudos e Pesquisas Educacionais Anísio Teixeira (Inep) e o Fundo Nacional de Desenvolvimento da Educação (FNDE) não chegaram a um consenso técnico.

Em junho de 2013, agregou-se ao debate para análise do parecer a Secretaria de Articulação com os Sistemas de Ensino (Sase). No início de 2014, após manifestação da Consultoria Jurídica do MEC (Conjur), o processo retornou ao CNE, com as observações dos órgãos do MEC.

Nesse mesmo ano funcionava um grupo de trabalho (GT) acerca do CAQ, sobre o qual já dissemos (SENA, 2017) que

O GT promoveu a oitiva de várias pessoas que atuam nos espaços políticos e institucionais. A multiplicidade de atores, a diferença de visões acerca de que insumos considerar (se a partir de "lista de insumos" ou por meio de formulação mais genérica), as propostas de associação ao Índice de Desenvolvimento da Educação Básica (Ideb), entre outros fatores, dificultaram o alcance de um consenso sobre a definição e metodologia do Custo Aluno-Qualidade (CAQ).

\section{$[\ldots]$}

Havia certo ceticismo no GT com relação à lista de insumos detalhada pela Campanha. Dizia-se, por exemplo, que escolas do campo não necessariamente precisavam de quadras esportivas. Na ocasião foi acentuado que "nem tanto ao mar, nem tanto à terra" - se não é possível acordar uma lista, por outro lado uma formulação genérica poderia ficar muito abstrata. Ao menos deveria haver um "núcleo duro de insumos" associado aos direitos tutelados. Como ponto de partida, ainda que houvesse variação segundo o perfil de cada município, a relação de demandas do Plano de Ações Articuladas (PAR) seria uma fonte de dados/inspiração para concretizar, na opinião do autor, o que era entendido em cada local como necessário para atender dado direito e, assim, compor um rol de insumos. Contudo, as autoridades do MEC consideravam - o que não deixou de ser um pouco surpreendente e frustrante - que o PAR não se prestava a esse exercício. Alternativamente, sugeriu-se considerar a relação de itens do SimCAQ² (SENA, 2017, p.286).

No caso de norma oriunda do executivo, o CAQ "bateu na trave" - em junho de 2014 havia sido aprovado o PNE que expressamente abrigou o CAQ e o Caqi, nos termos das estratégias 20.6 a 20.9: 
» implantação do Custo Aluno-Qualidade inicial - CAQi no prazo de dois anos (2016);

» implementação do Custo Aluno Qualidade - CAQ como parâmetro para o financiamento da educação de todas etapas e modalidades da educação básica, a partir do cálculo e do acompanhamento regular dos indicadores de gastos educacionais com investimentos em qualificação e remuneração do pessoal docente e dos demais profissionais da educação pública, em aquisição, manutenção, construção e conservação de instalações e equipamentos necessários ao ensino e em aquisição de material didático-escolar, alimentação e transporte escolar;

» definição do CAQ no prazo de três anos (2017), com base em metodologia formulada pelo Ministério da Educação - MEC;

» regulamentação do parágrafo único do art.23 e o art. 211 da Constituição Federal, no prazo de dois anos (2016) de forma a estabelecer as normas de cooperação entre os entes federados. O CAQ era elemento central das discussões das proposições legislativas sobre o tema ${ }^{3}$ - proposições que foram arquivadas;

» obrigação da União de, na forma da lei, realizar a complementação de recursos financeiros a todos os entes subnacionais que não conseguirem atingir o valor do CAQi e, posteriormente, do CAQ.

As propostas não foram implementadas. Houve, ainda, notícia de novos GT, que acabaram não decolando.

Em 2017, a Federação dos Municípios do Estado do Maranhão (Famem) propôs ação para obrigar o MEC a homologar a resolução do CNE que define valores de implantação do Custo Aluno-Qualidade inicial (CAQi). O pleito foi acolhido em primeira instância, mas cassado pelo Tribunal Regional Federal da 1ํㅡㄹ Região. Na Arguição de Descumprimento de Preceito Fundamental (ADPF) no 71 o tema foi debatido, tendo sido considerada prejudicada, em 19 de junho de 2019, por seu relator, ministro Gilmar Mendes. Também o Ministério Público Federal (MPF) do Rio de Janeiro ajuizou uma Ação Civil Pública (ACP 3484/2016).

Em 2019, o CNE, grave e, surpreendentemente, declarou-se não apto a "definir o valor financeiro e precificação do Custo Aluno-Qualidade Inicial (CAQi)". Ainda que o CNE não se julgue competente, a lei do PNE obriga a implementação do CAQ e do CAQi - "com base em metodologia formulada pelo Ministério da Educação MEC" (estratégia 20.8, PNE). 


\section{Qual a situação?}

OCAQ "não pegou" no Executivo (parecer não homologado, descumprimento das estratégias/metas do PNE, omissão do CNE em 2019 e do próprio Executivo). Não obteve sucesso no Judiciário e "ganhou, mas não levou" no Legislativo.

Isso tudo, a despeito da menção expressa à "qualidade", "padrão" e "padrão mínimo" em diversos dispositivos constitucionais: 206, VII (garantia de padrão de qualidade); $211, \S 1^{\circ}$ (padrão mínimo de qualidade); $212, \S^{3^{\circ}}$ (garantia de padrão de qualidade e equidade) e 214,III (melhoria da qualidade do ensino) - um oceano de previsões constitucionais expressas sobre a qualidade se transformou num continente de não efetividade.

Vale insistir em ação do Executivo, de preferência pela via do CNE? A meu juízo, vale. No Judiciário, posto que a Constituição Federal dá inúmeros pontos de apoio para sustentar que deve haver um parâmetro mínimo de qualidade, inclusive expressamente? Vale. No Legislativo? Sim, como ente que monitora o descumprido PNE.

Mas, o que parece fundamental é uma discussão técnica em amplo debate acerca de metodologias, gradualismos e federalismo para definir e implantar o CAQi e o CAQ, como determina a lei.

\section{Três Convergências necessárias}

Houve por um momento a má compreensão acerca da relação entre o CAQ e o Fundeb. Entendiam alguns que o CAQ substituiria o Fundeb. Isso não é possível, porque ambos têm natureza distinta: o Fundeb, oriundo da subvinculação de recursos à manutenção e desenvolvimento do ensino (MDE) é fonte e o CAQ é um critério de alocação de recursos que provém dessa e de outras fontes ${ }^{4}$, que devem - todas elas, o Fundeb e outras - levá-lo em consideração e alimentá-lo (SENA,2017).

Não só, CAQ e Fundeb são perfeitamente compatíveis, assim como o Fundeb é uma espécie de "escudo do CAQ", que poderá avançar se o caminho for aberto e protegido por aquele, inclusive e sobretudo, considerando a $\mathrm{EC} \mathrm{n}^{\mathbf{0}}$ 95/2016, que estabelece o teto de gastos de despesas primárias, com algumas exceções, entre elas a complementação da União ao Fundeb. Ademais, nesse momento debate-se o Fundeb Permanente por meio de uma Proposta de Emenda à Constituição (PEC) na Câmara dos Deputados (PEC n⿳0 15/2015), que acumulou dois anos de debates em cerca de quarenta audiências públicas, e duas proposições no Senado Federal: as PECs nº 33/2019 e 65/2019. Desde o início da tramitação na Câmara, foram propostos dispositivos que se referem a princípios cuja implementação muito contribui para a execução do financiamento e das políticas educacionais. Tanto a autora, deputada Raquel Muniz (planejamento na ordem social e proibição do retrocesso), como pela relatora (que acolheu esses e acrescentou outros: 
responsabilidade solidária e o Custo Aluno-Qualidade, como referência para o padrão mínimo definido nacionalmente).

Se a inserção do CAQ na Lei Ordinária do PNE não obteve, ainda, resultado concreto, sua inclusão na Constituição como princípio não é pouca coisa e deve ser celebrada, caso confirmada. É curioso que alguns críticos a essas propostas, à direita e à esquerda, argumentavam que a PEC só devia tratar do Fundeb, "focar" no Fundeb e que não era o caso de propostas "principiológicas". Ora, se há algum lugar no arcabouço normativo onde devem ser tratados os princípios, esse lugar é a Constituição. O princípio dará o fundamento e o vetor interpretativo da norma. Como afirma Cunha:

\begin{abstract}
Toda norma deve ser lida como se fosse o parágrafo de um artigo cujo caput compreende os princípios de que se irradia, e que justificam sua existência como norma é isso que se tem em vista ao afirmar que as normas devem ser aplicadas segundo seu espírito e não segundo sua literalidade aplicar uma norma contrariamente aos respectivos princípios é o mesmo que aplicar outra norma, inexpressa, ou talvez inexistente no sistema (CUNHA,2003, p.232).
\end{abstract}

Estar abrigado como princípio constitucional é o primeiro passo para a concretização do CAQ.

O grupo de trabalho que no âmbito do MEC, em 2015, discutiu critérios para a implementação do Custo Aluno-Qualidade (GT CAQ/2015) concluiu que o Fundeb é um poderoso mecanismo equalizador de recursos dentro de cada Unidade da Federação, mas, ainda assim, o valor total disponível por aluno para cada rede ou sistema de ensino permanece desigual. Municípios pobres em estados comparativamente mais ricos não recebem a complementação enquanto municípios ricos, mas cuja riqueza não é captada se o olhar se limitar à cesta do Fundeb, recebem complementação. Esta constatação foi o fator que motivou o desenvolvimento da ideia de adotar como critério, para a complementação, o "valor aluno-ano total" (MARTINS, 2018b).

Nesse contexto, o consultor de Orçamento e Fiscalização Financeira da Câmara dos Deputados, Cláudio Tanno, elaborou o Estudo Técnico nº 24/2017-CONOF/CD (Outubro/2017), em que propôs a adoção como critério para distribuição dos recursos da complementação, do que denominou valor aluno ano total (VAAT), que considera todas as fontes vinculadas à MDE, mesmo as que não estão na cesta-Fundeb (ISS, ITBI, IPTU), quando se calcular a complementação. Ao mesmo tempo, a complementação não seria mais feita por âmbitos estaduais, mas por redes. Desta forma, algumas redes municipais - não todas - de estados que hoje não recebem a complementação da União passariam a desfrutar do benefício.

A principal inovação proposta pela relatora da PEC nº 15/2015, deputada Prof ${ }^{\text {. }}$. Dorinha Seabra Rezende, em sua primeira minuta de substitutivo, foi a adoção, para a complementação, do critério do VAAT. Nessa primeira versão, apresentada na 55a legislatura, eram previstas duas modalidades de complementação: a "modalidade 1", seria 
referente aos 10\% dos recursos, cuja distribuição continuaria segundo os mesmos critérios atuais: por âmbitos estaduais. A partir daí os recursos acrescentados fariam parte da "modalidade 2", distribuída por rede que não alcançasse o valor aluno ano total. Assim, já no primeiro ano, segundo aquela proposta, dez por cento seriam distribuídos por âmbito estadual, segundo o Valor Aluno-Ano do Fundeb e cinco por cento conforme o Valor Aluno-Ano total. Nos anos subsequentes, todos os acréscimos seriam distribuídos conforme o VAAT, até que vinte por cento respeitassem esse critério e dez por cento o critério antigo. A partir da complementação da União de 15\%, nenhum âmbito estadual perderia, embora internamente fossem feitas redistribuições.

A segunda versão da minuta, a partir do entendimento de que deveria haver a distribuição que atenda ao critério do VAAT previa sua adoção total e imediata.

O conceito do VAAT harmoniza-se com o entendimento de que o CAQ é alimentado por todas as receitas disponibilizadas para a educação. Sua adoção como critério para a complementação da União deve, para considerar o CAQ em sua integralidade, reconhecer o que houve de planejamento e gestão e observar que há entes potenciais perdedores de recursos - que não são seus, são da complementação da União - mas com os quais contaram ao longo dos últimos anos. Da mesma forma, não se pode olvidar que, no caso dos estados, há aqueles que destinam recursos a universidades estaduais, inclusive por determinação de sua Constituição. Não seria admissível - e surgiriam conflitos jurídicos - que o poder constituinte derivado federal atropelasse o poder constituinte originário estadual, num regime federativo. Aqui, o instrumento desenvolvido para dar suporte técnico ao CAQ, como ferramenta de gestão, o SIMCAQ, pode auxiliar no mapeamento daquilo que se avançou em redes que obtiveram ou se aproximaram do CAQ e poderiam ser afetadas com o VAAT, se não houver esse cuidado. Para que esse processo tenha a cautela necessária, uma alternativa é, como constava da primeira minuta da relatora, e foi retomada na minuta de 18 de setembro de 2019 - adotar o chamado "modelo híbrido", que mantém parte da complementação - os 10\% atualmente considerados com as regras atuais e distribuição dos acréscimos segundo o VAAT na "modalidade 2" de complementação da União. Outra possibilidade seria a fixação de transição até a adoção do modelo do VAAT pleno, período em que os dados do SimCAQ poderiam orientar o ritmo e a forma da transição.

Na realidade, há uma situação de fato que indica que pode haver a necessidade de uma outra transição de, possivelmente, três anos. Isto porque o VAAT considera - não para efeito da cesta do Fundeb, que permanece inalterada - para distribuição da complementação da União os impostos municipais, sobre os quais há dúvidas quanto à fidedignidade das informações obtidas por processo declaratório. Mas, nesse modelo, qualquer incorreção nos dados de um ente afeta os demais.

Já a pesquisa "Perfil dos gastos educacionais nos municípios brasileiros - ano base 2009", promovida pela Undime, sob a coordenação de Raimundo Luiz Silva Araújo, 
indicava que as informações disponíveis sobre os custos da educação municipal estavam imprecisas (ARAUJO, 2012). Em relação a dados de impostos municipais, às receitas e despesas com educação, o ente deve informar ao Sistema de Informações sobre Orçamentos Públicos em Educação (Siope), à Secretaria do Tesouro Nacional (STN) e ao respectivo tribunal de contas. Técnicos do FNDE apontam que, eventualmente, os dados não conferem e, também, há casos em que o ente - estado ou município - ingressa com ação na Justiça para não informar e obtém liminar (procedimento que vai sendo periodicamente repetido).

Em audiência pública da Comissão Especial do Fundeb, em 13 de junho de 2019, Vanessa Lopes de Lima, secretária de Controle Externo de Educação do Tribunal de Contas da União (TCU) apontou:

Temos várias questões de judicialização acerca dos recursos do Fundeb. Estados que não recebem complementação acabam judicializando para não registrar os dados do Fundeb. Isso prejudica o acompanhamento, tanto do ponto de vista dos órgãos de controle quanto do ponto de vista do controle social.

Se pudermos avançar em algo que privilegie a transparência e, de alguma forma, concentre as informações sobre os recursos do Fundeb numa única plataforma, que permita ter rastreabilidade, confiabilidade, comparabilidade dos dados, vai permitir que façamos análises mais criteriosas, avaliações mais consistentes sobre a utilização desses recursos e como eles ser revertem na qualidade da educação.

Na mesma audiência, Sylvia Cristina Toledo Gouveia, então coordenadora-geral de Operacionalização do Fundeb e de Acompanhamento e Distribuição de Arrecadação do Salário-Educação do FNDE, afirmou:

\footnotetext{
Sobre o Siope, além da necessidade de pontuarmos que ele ainda não tem uma base constitucional e legal sólida, o que dificulta sobremaneira a gestão do sistema em virtude da judicialização e do grande número de ações judiciais movidas pelos entes governamentais que têm certa resistência em promover a declaração dos dados, é importante observar também que a aproximação com os tribunais de contas e com os demais órgãos de controle é muito importante para que nós consigamos trabalhar e avançar na consistência dos próprios dados.
}

Na audiência seguinte, em 18 de junho de 2019, Ernesto Carneiro Preciado, coordenador-geral de Análise, Informações e Execução de Transferências Financeiras Intergovernamentais, da Secretaria do Tesouro Nacional, do Ministério da Economia, esclareceu acerca do desenvolvimento da Matriz de Saldos Contábeis (MSC) que obtém informação a partir da movimentação contábil de balancete do município, portanto, informações completas de toda a receita e de toda a despesa. O encaminhamento dos dados é obrigatório, desde janeiro de 2018 para a União, estados, Distrito Federal e capitais. A partir de julho de 2019, passa a ser obrigatório para os demais municípios. Nessa audiência o expositor concluiu: 
Então, em resumo, um recado que eu gostaria de passar aqui, em nome do Tesouro, é a importância da Matriz para esse avanço que nós estamos tendo em termos de transparência de padronização e de dados. E reafirmar que a implantação efetiva da Matriz é fundamental para essa melhora que nós estamos querendo fazer na sistemática de distribuição do Fundeb.

Não há dúvida quanto à importância da Matriz. Ocorre que, sua efetiva implantação pode requerer, para ser uma base completa e segura, o prazo de até três anos, na avaliação de alguns técnicos. Daí a necessidade regras de transição, para apurar ou estimar os recursos de impostos municipais, no caso de não estarem os dados mais precisos disponíveis no momento da vigência. A ausência de dados que gera a necessidade de transição acarreta inevitavelmente algumas distorções nesse período, mas será o preço do aperfeiçoamento do modelo a partir de sua estabilização.

E, tanto para a transição, como para um desenho permanente do novo Fundeb, é importante que o SimCAQ e o VAAT conversem.

\section{CAQ, (Sub)Vinculação e Federalismo}

OCAQ tem no Fundeb seu escudo. O Fundeb é uma subvinculação. Sem a vinculação, não há Fundeb. Perece o instrumento federativo de equalização, que é a complementação da União.

O que os fundos contábeis fizeram, a partir dos anos 90 do século passado, foi organizar a vinculação - o que permitiu a segurança do fluxo de recursos e, assim, o aprimoramento do planejamento e da gestão. Graças a esses recursos vinculados os municípios podem planejar e executar suas ações. Com a vinculação de recursos de impostos da União e dos estados, abre-se a possibilidade de que realizem as suas tarefas e exerçam as funções supletiva e redistributiva (art. 30, VI e art. 211, $\S \S 1^{\circ}$ e $3^{\circ}, \mathrm{CF}$ ).

Não deixa de ser surpreendente que circule em corredores do Poder Executivo proposta ironicamente denominada de "novo pacto federativo", que propõe a desvinculação de recursos à educação. Conforme assentado em "Manifesto pela manutenção da vinculação de verbas para a educação pública na Constituição Federal de 1988", da Associação Nacional de Pós-Graduação e Pesquisa em Educação (Anped):

A proposta de desvinculação que vem sendo cogitada pelo governo é essencialmente uma proposta antifederativa, que trará graves prejuízos, sobretudo ao financiamento pelos municípios.

Em primeiro lugar, porque é a vinculação que permite aos entes exercerem sua função supletiva e dá os meios para que organizar a educação em seu território para atender as funções prioritárias estabelecidas no art. 211 da constituição. Em segundo lugar, a desvinculação implica o fim do FUNDEB. O Fundeb é uma subvinculação. A desvinculação extinguirá esse mecanismo de financiamento que se caracteriza por 
repasses automáticos com instrumentos de controle interno, externo e social e tem critérios redistributivos, segundo a matrícula, destina recursos, por meio de outra subvinculação, à remuneração dos professores. Sem a vinculação, a cesta do Fundeb é furada, se não, inexistente. O instrumento, ainda insuficiente no Fundeb, mas simbólica e materialmente importante, a complementação da União ao Fundeb também desapareceria. O que provocaria o caos nos sistemas públicos estaduais e municipais.

A proposta ignora o modelo federativo adotado pela Carta de 1988 e trará novos conflitos federativos e provável judicialização. Ainda que houvesse a desvinculação na Constituição Federal, continuam válidas as normas de vinculação estabelecidas, por vezes em patamar superior aos $25 \%$, em várias constituições estaduais e das leis orgânicas municipais. O poder constituinte originário estadual ou municipal assim decidiu. Não pode ser atropelado pelo poder constituinte federal derivado, em desrespeito ao pacto federativo.

A desvinculação de recursos de impostos à manutenção e desenvolvimento do ensino, a par de inconstitucional, por violar cláusula pétrea, é antifederativa. Desorganiza os meios de financiamento e a reserva de recursos para o exercício da função supletiva. Destrói a política de cooperação, o regime de colaboração (ANPED, 2019).

\section{Do Fundeb federativo ao CAQ federativo}

Como já pude assinalar (MARTINS, 2011), a questão federativa é um tema que não tem sido bem equacionado no debate acerca do financiamento da educação. Seja no âmbito acadêmico ou no movimento social, desconsidera-se frequentemente a forma assumida pelo Estado brasileiro e procura-se com ele interagir como se fosse um Estado Unitário. Considera-se que o esforço financeiro e administrativo cabe unicamente ao Governo Central, confundindo-se a esfera federal com o Estado Brasileiro ${ }^{5}$. É claro que

em uma federação assimétrica como a nossa a capacidade de incidir sobre as referidas desigualdades depende da União, pois a capacidade dos estados e, em especial dos municípios, de reverter as desigualdades territoriais somente seria viável com mudanças estruturais na política tributária e revisão profunda do pacto federativo existente (ARAUJO, 2013).

Mas, desde a implementação da política de fundos, com o antigo Fundef, foi gerada "maior consciência intergovernamental" no sentido de exercício da solidariedade. (ABRUCIO, p.64). E com o advento do Fundeb (SENA, 2008):

» foi constitucionalizada a regra de contribuição da União, via complementação ao Fundeb, e se definiu um patamar mínimo de alocação de recursos federais (10\% do valor dos fundos), que teve avanços significativos, adequados ao federalismo cooperativo, com alguns resultados concretos no que se refere à diminuição das desigualdades regionais - embora de maneira ainda insuficiente; 
criou-se uma instância de formulação, debate e negociação federativa, a Comissão Intergovernamental de Financiamento para a Educação Básica de Qualidade, que incluiu a dimensão regional;

possibilitou-se a setorização da lei complementar (prevista no art. 23, parágrafo único, que teve nova redação com a EC 53) para disciplinar a cooperação entre os entes federados na esfera educacional, que passa a ser um dos desafios da agenda para a consolidação do Fundeb.

O CAQ, tal como aparece no PNE ainda se coloca dependente da União, que, na forma da lei, deve realizar a complementação de recursos financeiros a todos os entes para alcançá-lo. Evidentemente, cabe à esfera que tem maior poder político e financeiro e, portanto, maior responsabilidade, apoiar os demais entes e assumir maior compromisso, já que o papel redistributivo do Governo Federal é importante para reduzir desigualdades interjurisdicionais (ARAUJO, 2016).

Ao destacar que o Custo Aluno Qualidade Inicial é, também, uma proposta de justiça federativa, Cara assinala:

Além das desigualdades regionais, há as desigualdades entre os estados, mesmo entre aqueles localizados em uma mesma região e também entre os municípios inclusive, em relação a cidades localizadas em estados diferentes ou em um mesmo estado. Essa realidade compõe uma espécie de desigualdade federativa horizontal, ou seja, manifesta entre entes subnacionais do mesmo tipo. Em outras palavras, essa categoria compreende as desigualdades entre os estados como pares e também as assimetrias verificadas no conjunto dos municípios entre si (CARA, 2014, p.79).

Se o VAAT e o CAQ são instrumentos potentes para distribuir mais equitativamente a complementação da União, ao mesmo tempo constituem-se em indicadores reveladores da desigualdade intraestado. Este aspecto, particularmente, suscitou, nas discussões da equipe técnica das consultorias do Congresso Nacional que assessora os relatores das PECs referentes ao Fundeb Permanente ${ }^{6}$, além de debates sobre o modelo híbrido e VAAT pleno, o "modelo Alisson", proposto para discussão pelo consultor legislativo Alisson Minduri Capuzzo e cuja preocupação é que a complementação por rede, que mira a minimização da desigualdade intermunicipal esteja associada ao não aumento da desigualdade interestadual. Nas palavras de seu proponente, deveria

ser considerado, como critério de distribuição da complementação da União, além do VATT município a município, o VAAT médio do âmbito estadual em que o município está inserido, ou seja, a ordem de distribuição da complementação da União começaria pelos municípios com VAAT mais baixo dentro dos âmbitos estaduais com VATT médios mais baixos (iríamos " enchendo" os municípios mais pobres até que o VATT médio daquele âmbito estadual se igualasse ao do próximo e assim por diante. Metodologia parecida com a que temos hoje, mas com o aprimoramento que seria considerar o VATT médio estadual -e não mais o valor Fundeb - e complementando apenas para os municípios abaixo desse VATT médio. Ou seja, 
complementação apenas para os municípios mais pobres dos estados mais pobres (CAPUZZO, 2019).

O "modelo Alisson" traz um insight importante acerca da preocupação com a desigualdade interestadual e, implicitamente, convoca, na perspectiva da solidariedade federativa, cada âmbito estadual a contribuir para minimizar suas desigualdades internas, isto é, a não depender apenas de ação da União. Haveria menos capilaridade - elemento que pode ser importante como indutor de outras políticas. Opinou-se, também, que para que o modelo funcionasse plenamente seria importante enfrentar tema que já consta da LDB desde sempre (Art.75, $\S 1^{\circ}$ ), que é "a medida do esforço fiscal”. De qualquer forma, coloca a questão na pauta de discussões.

Esta resposta, de um CAQ federativo e o caminho para a convergência entre o CAQ e o Fundeb, o CAAQ e o VAAT e o CAQ e a federação cooperativa são os desafios imediatos para o debate do financiamento da educação básica de qualidade.

Recebido em: 21/09/2019 e Aprovado em: 06/10/2019

\section{Notas}

1 Essa ideia síntese estava amadurecendo em debates que envolviam naquele momento outros importantes precursores da pesquisa em financiamento da educação, como Messias Costa, Jacques Velloso, Cândido Gomes e João Monlevade.

2 Segundo consta na plataforma on line "o Simulador de Custo-Aluno Qualidade (SimCAQ) é um sistema gratuito e disponível na internet (www.simcaq.c3sl.ufpr.br) cuja finalidade é subsidiar o cálculo do custo da oferta de ensino em condições de qualidade nas escolas públicas de educação básica e subsidiar a elaboração do orçamento público para assegurar um financiamento adequado nos níveis municipal, estadual e nacional". Assim como o Fundeb teve poder indutor de políticas, procedimentos e instrumentos, o CAQ tem como legado, entre seus subprodutos, essa ferramenta de planejamento orçamentário, que realiza o diagnóstico do contexto educacional dos entes federados e calcula o orçamento necessário para garantir o financiamento da educação em condições de qualidade na localidade selecionada.

3 OCAQ foi abrigado em propostas referentes ao sistema nacional de educação e regulamentação do Art.23, parágrafo único da Constituição, referente à cooperação federativa. O PLP nº 413/2014, de autoria do deputado Ságuas Moraes e o PLP 15/2011, cujo relator - de ambos - era o deputado Glauber Braga, foram, regimentalmente, arquivados ao fim da $55^{\mathrm{a}}$ legislatura. O PLP no 25/2019 tematiza a cooperação, mas não faz referência expressa ao CAQ. Assim, a proposição que inclui o CAQ, atualmente em tramitação, é o PL $\mathrm{n}^{\circ} 7420 / 06$, de autoria da deputada Raquel Teixeira, cujo tema central é a responsabilidade educacional e foi relatado pelo deputado Bacelar.

4 Quando se analisa a matriz do CAQ produzida pela Campanha Nacional pelo Direito à Educação (CARREIRA e PINTO, 2007, p.26) verifica-se que são considerados insumos referentes a condições de estrutura e funcionamento: valorização dos profissionais, gestão democrática e acesso e permanência. Ora, despesas com estrutura e políticas de permanência têm sido financiadas, também, com recursos do salário-educação, que é outra fonte, advinda de contribuição social e não de imposto. Da mesma forma, os royalties, que são considerados como de natureza indenizatória, embora haja posições no sentido de entendê-los como tributos - o que de qualquer maneira não seria do gênero "imposto". Esta percepção, se bem captei sua po- 
sição, tenho partilhado, há anos, com o prof. Vander Bastos, que atuou desde o início da política de fundos, no FNDE. O CAQ não se resolve somente com o Fundeb.

5 Assim, surgem propostas como federalização da carreira docente, hierarquização por esferas, entre os conselhos de acompanhamento do Fundo, responsabilidade única da União pela equalização do CAQ, olvidando-se o princípio da solidariedade federativa, que envolve todos os entes. A todos cabe a responsabilidade solidária de garantir o direito à educação.

6 Tramita na Câmara dos Deputados, a PEC nº 15/2015, cuja primeira signatária é a deputada Raquel Muniz e a relatora a deputada prof ${ }^{\mathfrak{a}}$ Dorinha Seabra Rezende. No Senado Federal, tramitam as PECs nº 33/2019 e 65/2019, respectivamente do senador Jorge Kajuru e dos senadores Randolfe Rodrigues e Davi Alcolumbre, sendo relatores os senadores Zequinha Marinho e Flavio Arns. As consultorias das duas casas, por orientação dos relatores, realizam debates técnicos da equipe composta pelos consultores legislativos da Câmara - Ana Valeska Amaral Gomes, Ricardo Martins, Alisson Minduri Capuzzo, Mauricio Holanda Maia e Paulo Sena, pelos consultores de orçamento e fiscalização financeira da Câmara, Cláudio Riyudi Tanno e Marcos Rogerio Rocha Mendlovitz e pelos consultores legislativos do Senado José Edmar de Queiroz, Paula Emerick Corrêa e Tatiana Feitosa de Britto e pelo consultor de orçamento do Senado Murilo Carvalho.

\section{Referências}

ABRUCIO. Fernando Luiz. A dinâmica federativa da educação brasileira: diagnóstico e propostas de aperfeiçoamento, p. 39-70. In: OLIVEIRA, Romualdo Portela de; SANTANA, Wagner (Orgs.). Educação e federalismo no Brasil: combater as desigualdades, garantir a diversidade. Brasília: UNESCO, 2010.

ARAÚJO, Raimundo Luiz Silva. Desvendando o perfil dos gastos educacionais dos municípios brasileiros. Educação \& Sociedade, Cedes: Campinas, v. 33, n. 121, p. 1215-1233, 2012.

. É possível diminuir as desigualdades entre os municípios brasileiros por meio de uma política de fundos na educação? Fineduca, Porto Alegre v. 3, n. 12, p. 1-14 (Fineduca adota o formato de publicação contínua) , 2013. Disponível em http://seer.ufrgs.br/fineduca. Acesso em: 14 de julho de 2019.

2016.

. O CAQ e o novo papel da União no financiamento da educação básica. Jundiaí: Paco Editorial,

ASSOCIAÇÃO NACIONAL DE PÓS-GRADUAÇÃO E PESQUISA EM EDUCAÇÃO. Manifesto pela manutenção da vinculação de verbas para educação pública na constituição federal. Publicado em 22/04/2019. Disponível em: http://www.anped.org.br/news/manifesto-pela-manutencao-da-vinculacaode-verbas-para-educacao-publica-na-constituicao-federal. Acesso em: 14 de julho de 2019.

BRASIL. Câmara dos Deputados. Comissão Especial destinada a proferir parecer à Proposta de Emenda à Constituição nº 15-A, de 2015. 9ª reunião ordinária - Audiência pública. Sessão de 13 jun. 2019. Brasília, 2019. Notas Taquigráficas.

Câmara dos Deputados. Comissão Especial destinada a proferir parecer à Proposta de Emenda à Constituição no 15-A, de 2015. 10ª reunião ordinária - Audiência pública, Sessão de 18 jun. 2019. Brasília, 2019. Notas Taquigráficas.

. CNE. PARECER CNE/CEB №8/2010. Estabelece normas para aplicação do inciso IX do artigo $\mathbf{4}^{\circ}$ da Lei no 9.394/96. Brasília, 2010. Disponível em: <www.mec.gov.br> Acesso em: 14 de julho de 2019.

. Emenda Constitucional no 53, de 19 de dezembro de 2006. Dá nova redação aos arts. 7º , 23, 30, 206, 208, 211, 212 da Constituição Federal, e ao art. 60 do Ato das Disposições Constitucionais Transitórias. Disponível em: <www.planalto.gov.br>. Acesso em: 14 de julho de 2019. 
. Emenda Constitucional no 59 , de 11 de novembro de 2009. Acrescenta $\S 3^{\circ}$ ao art. 76 do Ato das Disposições Constitucionais Transitórias [...] e dá nova redação ao $\S 4^{\circ}$ do art. 211 e ao $\S 3^{\circ}$ do art. 212 e ao caput do art. 214, com a inserção neste dispositivo de inciso VI. Disponível em: <www.planalto.gov.br>. Acesso em: 14 de julho de 2019.

Lei no 9.424, de 24 de dezembro de 1996 (Lei do Fundef). Dispõe sobre o Fundo de Manutenção e Desenvolvimento do Ensino Fundamental e de Valorização do Magistério, na forma prevista no art. 60, $\S 7^{\circ}$, do Ato das Disposições Constitucionais Transitórias, e dá outras providências. Acesso em: $12 \mathrm{dez}$. 2009.

Lei no 9.394, de 20 de dezembro de 1996 (LDB). Estabelece as diretrizes e bases da educação nacional. Acesso em: 12 dez. 2009.

Lei no 10.172, de 09 de janeiro de 2001 (PNE 2001-2010). Aprova o Plano Nacional de Educação e dá outras providências. Acesso em: 12 dez. 2009.

Lei no 13.005, de 25 de junho de 2014(PNE 2014-2024). Aprova o Plano Nacional de Educação PNE e dá outras providências. Acesso em: 14 de julho de 2019Acesso em: 12 dez. 2009.

Relatório Final. GT CAQ Portaria MEC 459, de 12 de maio de 2015. Brasília, outubro de 2015.

CAPUZZO, Alisson Minduri. VAAT médio do âmbito estadual como critério para a complementação da União ao Fundeb. Documento de trabalho, 2019.

CARA, Daniel. O Custo Aluno-Qualidade Inicial como proposta de justiça federativa no PNE: Um primeiro passo rumo à educação pública de qualidade no Brasil. Jornal de Políticas Educacionais. $n^{\circ} 16$. julho-dezembro de 2014. pp. 75-91.

CARREIRA, Denise e PINTO, José Marcelino Rezende. Custo aluno-Qualidade Inicial: rumo à educação pública de qualidade no Brasil. São Paulo: Campanha Nacional pelo Direito à Educação/Global Editora, 2007.

CUNHA, Sérgio Sérvulo da. O que é um princípio? p.225-240. In: Cadernos de Soluções Constitucionais, vol. 1, Col. Soluções Constitucionais. São Paulo: Malheiros/ABCD, 2003.

MARTINS, Paulo de Sena. FUNDEB, federalismo e regime de colaboração. Campinas: Autores Associados, 2011.

. Constituinte, Financiamento e direito à educação: a voz dos protagonistas. Educ. Soc., Campinas, v. 39, no 2.145 , p.823-845, out./dez. 2018a.

O fim do prazo de vigência do Fundeb e as perspectivas para o Fundeb permanente. In: Cadernos Aslegis, nº 55. Brasília: Associação dos Consultores Legislativos e de Orçamento e Fiscalização Financeira da Câmara dos Deputados, p. 57-74, 2018b.

O direito à educação na Carta Cidadã. Revista de Informação Legislativa, Brasília, v. 56, n. 221, p. 223-246, jan./mar. 2019.

MELLO, Ediruald de. Implicações do financiamento da Educação na Gestão Democrática do ensino público de primeiro grau. Em Aberto, Brasília, n. 42, p. 51-54, abr/jun. 1989.

Os desafios do ensino público de qualidade para todos. Revista Brasileira de Administração da Educação, [s.l.], v. 7, n. 1/2, p. 132-137, jan./dez. 1991.

SENA, Paulo. A legislação do Fundeb. Cadernos de Pesquisa, FCC: São Paulo, v. 38, n. 134, p. 319-340, maio/ago. 2008. 
. O Financiamento da Educação de Qualidade. Revista Educação e Políticas em Debate, Uberlândia, v. 3, n. 2, p. 268-290, ago./dez. 2014.

O Sistema Nacional de Educação (SNE) e o Custo Aluno-Qualidade (CAQ): as metas estruturantes para o cumprimento do PNE subiram no telhado? p.274-304. In: GOMES, Ana Valeska Amaral (Org.). Plano Nacional de Educação: olhares sobre o andamento das metas. Brasília: Câmara dos Deputados, Edições Câmara, 2017. 